International Journal of Advanced Trends in Computer Science and Engineering

Available Online at http://www.warse.org/IJATCSE/static/pdf/file/ijatcse141922020.pdf

https://doi.org/10.30534/ijatcse/2020/141922020

\title{
Location Specific Rice Crop Variant Suitability using Data Mining Technique
}

\author{
Arvin N. Natividad ${ }^{1}$, Luisito L. Lacatan ${ }^{2}$ \\ ${ }^{1}$ Doctor in Information Technology in AMA University, Quezon City, Philippines. arvinnatividad05@ gmail.com \\ ${ }^{2}$ Dean of College of Engineering in AMA University, Quezon City, Philippines. 1llacatan@ maes.edu.ph
}

\begin{abstract}
Filipino has been regarding rice as one of the most important foods for centuries. Rice farmers had faced crop-related issues in the previous years that had a major impact on the rate of rice production and resulted in low importation rate. There have been several factors that affects rice production for the specific planting field, such as soil fertility, biological restrictions and unsuitable variant of rice quality. Several research was conducted to provide solutions through the collaboration of various fields such as information technology and farming. Design of computer technology and prototypes for data collection, storage, processing, and analysis to increase rice production. The study focused on the determine the suitable data mining algorithm and historical data of rice harvest and rice field characteristics can be used to utilized for the development of prediction system that will accept current data and analyzed based form the predictive algorithm used in the system that will produce a predictive output of what suitable rice crop variety for the specific rice field. Result from the predictor can be used as reference of the farmers, agriculturists and Office of Provincial Agriculturist in helping rice farmers in selecting rice crop variant resulting for a better yield.
\end{abstract}

Key words : Agricultural data mining, Algorithm, Decision Tree, Rice crop suitability

\section{INTRODUCTION}

Rice (Oryza sativa L.) as one of the main food crop of almost half of the world's population, not only being a staple food, production and importation was also an important source of livelihood and employment of several rural areas worldwide particularly in South East Asian country. Requiring at least $1 \%$ increased rice production rate per annum could lead to delivering sufficient food supply to ever-growing population in most-consuming countries like Asia [1]. The key approach to achieve this goal of increasing global rice production is to select the suitable rice crop variety such as hybrid rice, according to Food and Agriculture Organization (FAO). It has almost $15-30 \%$ yield advantage over inbred rice varieties [2], yet still the higher grain yield from hybrid rice depends on the environment interaction and other rice field factors.

There have been several research works nowadays were being presented and implemented to increase rice yield. With the collaboration of different field such as Agriculture, Information technology and Data Science, most of the issues about rice production were addressed. The use of information technology and data mining in the field of agriculture will improve the situation of experts and farmers in decision making in a better way. The production of agricultural data is a relatively new technique for yield predictions and crop management. Agricultural issues and problems such as limited knowledge in the use of raw agricultural data open up an innovative new direction that led to the exploration of new technology and techniques such as data mining. Data mining techniques could generate information such as prediction results and finding patterns that will help farmers for crop evaluation.

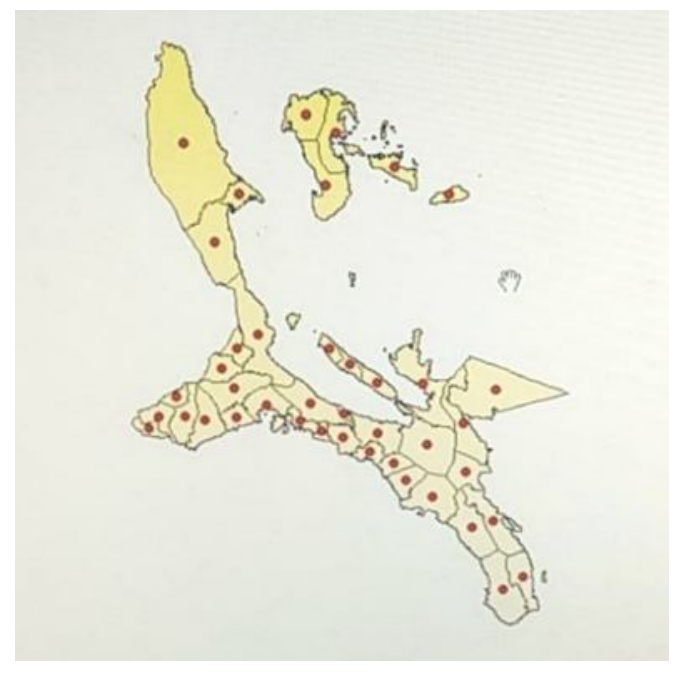

Figure 1: Map of Quezon and its municipality

As shown in Figure 1 is the map with pointers of different municipalities in the province of Quezon, considered the 8th largest province in the country and the largest agricultural producer in the CALABARZON region (Cavite, Laguna, 
Batangas, Rizal and Quezon) in terms of the farm system implemented from its 39 municipalities and 2 cities, as revealed by a survey of 513,618 hectares of agricultural land [3] conducted by the Philippine Statistics Authority (PSA).

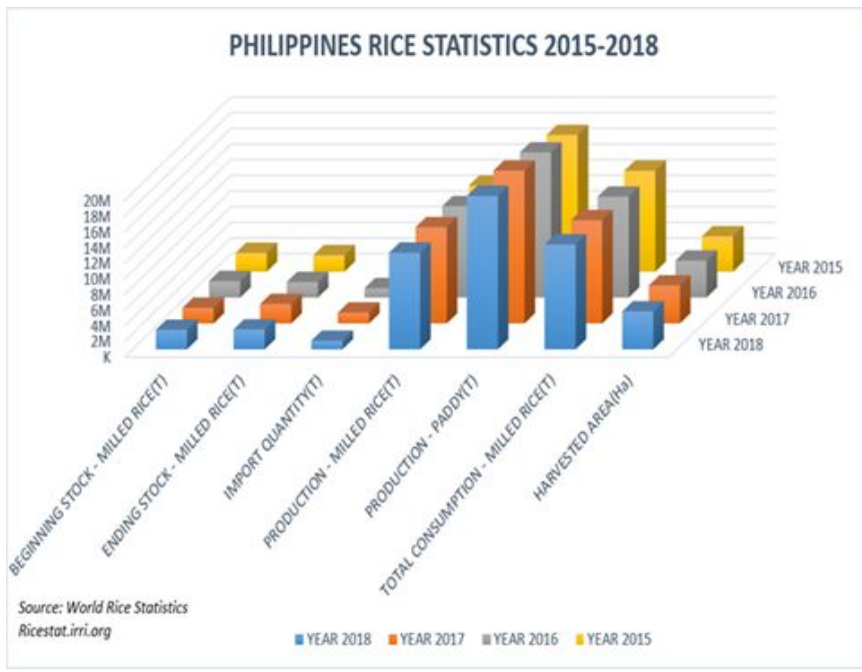

Figure 2: Philippines Rice Statistics 2015-2018

During the year 2018, CALABARZON region was projected to have bigger rice harvest in during the first semester from its 59, 623 hectares of rice field. Based from the data coming from Philippine News Agency the province of Quezon [4], rice production is one of the biggest contributor for in the region. Annually the province of Quezon alone could supply nearly 200,000 MT of maize and rice, or nearly $42 \%$ of the total region's maize and rice requirement.

Some parts of the province of Quezon are still in less critical state in terms of rice production, some of the reasons for this are, reduction in the number of agricultural areas due to land conversion from agricultural to residential, poor quality agricultural infrastructure, poor irrigation systems, natural disasters resulting in overflowing river systems, droughts, less support for farmer's education on good farming practices and more.

Government and private sectors join hand in hand to address the issues faced by rice farmers and improve agricultural outputs. Agriculturist and experts proposed several projects such as new agricultural practices as response to increased climate risks, technology on Rice-Based agroforestry [5], allocation of additional funds for the improvement of irrigation systems [6], soil nutrient management, pest management system, improvement in research and development for higher rice yield.

Today, several researches and projects has been done most of them are combination of Agriculture and Data Science as well as Information Technology field to improve rice yield.
Precision agriculture [7], Smart space technology [8], MCU based soil nutrient analyzer device [9] and smart farming [10] are some of the most popular research which includes data collection from the environment such as temperature, air quality, humidity, soil nutrient, crop maturity, farming equipment, labor costs and availability of existing data in real time.

Data mining is another methodology used for improving the yield rate of rice and other crops. Data mining uses techniques at the intersection of information systems, Artificial Intelligence, machine learning, statistics and data. A process of extracting knowledge and implicit information from large databases [11]. Based from the research study of Ganesh et al., j48 algorithm [12] could be utilized to predict soil fertility requires data set for analysis. Data sets that contains various attributes, series of soil samples values and the area where the soil sample was collected and soon to be mined to acquire useful information for the rice farmers.

The aim of the study was to test the data using different data mining algorithm and techniques, the data to be tested are from the Provincial Agriculturist Office rice production rate in selected municipalities of Quezon and soil analysis data from soils lab. The tested and selected algorithm that could provide better and accurate output will be used for the development of a predictive system for choosing suitable rice crop variant that will have a better yield for specific rice field.

\section{RELATED WORKS}

The related literature and studies discusses different research components, the previous technologies, techniques, methods, prediction and data mining applicable for agriculture and yield prediction.

\subsection{Soil Nutrient}

Yousaf et al. discusses, one of the important factor for plant growth and development to sustain crop productivity relies on continuous renewal of soil nutrients. However, excessive and inappropriate application of fertilizer would result low nutrient efficiency [13], occurs negative effect on the diversity of soil organism [14], could cause environmental issues in agro-industry, and does not guarantee increasing of yield. It is necessary to determine the presence and status of soil nutrients such as Nitrogen, Phosphorus and Potassium before planting on the rice field. There are some factors to take into account such as type of ecosystem and rice genotypes, e.g. hybrid and inbred, to smooth out small-scale spatial variations in nutrient supplies among variants that requires further investigation. Utilizing integrated nutrient management [15] method in which both inorganic fertilizers and organic manures used simultaneously in maintaining 
sustainable and healthy soil system. Furthermore, determining important factors and abovementioned methods can be used for proper fertilizer application as well as influences yields directly.

\subsection{Rice Variant}

According to Dubey, the performance of rice varieties is assessed on the basis of their seasonal and locational stability. Choosing a variety of rice to plant depends on many factors. High yield [16] is often considered one of the main reasons for choosing the right rice crop variety. Aside from those reason, based from the previous studies there are some other factors or determinants of varietal diffusion and adoptions such as, tenure status, farm size, farmers education and credit services offered to the farmers community [17]. Other important considerations are the perceived qualities of the variety, as well as its marketability (price). The latter relies on customer and other players in the rice value chain, such as distributors, millers, wholesalers, and retailers, for the grain quality preferences.

\subsection{Geospatial}

Based from the study of Amin et al., chemical and physical properties of soil, topography and climate were selected based from local expert knowledge on rice farming as primary data for land suitability analysis [18]. As an additional data from the published journals and literature, other six casual factors were included such as soil texture, soil PH, soil depth, slope, temperature, rainfall and climatic condition [19].

GIS technology can also be incorporated to precision farming as one of the most popular agricultural approach involving the adaptation of advanced technologies helps farmers in reducing processing task as well as time and effort to accomplish certain task. Ayehu et al., cited application of precision farming through the utilization of Geospatial Information System for Decision Support system tool bring benefits to managers and farmers in managing paddy fields as well as enhancing their skills in ICT [20]. The decision support system tool accepts spatial and attribute data such as soil data, yield data, pest records and fertilizer recommendation from multiple data sources. DSS has the capability of analyzing data to turn in to meaningful information for better management of variation within paddy fields.

\subsection{Data Mining in Agriculture}

According to Poonia et al., in the field of agriculture, the utilization of information technology and data mining can improve experts and farmers decision-making situation in a better way [21]. Agricultural data extraction is a relatively new methodology for predicting crop and plant management.
Issues and problems in agriculture such as limited knowledge in using the raw agricultural data opens new an innovative way that led to exploring new technologies and techniques such as data mining. Raorane et al. cited that using those techniques that produces information such as production performance and discovering patterns that will be beneficial for farmers for crop assessment [22].

\subsection{Decision Tree}

Classical statistical method may not be adequate in finding a cause-and-effect relationship between variables and yield specially if the agricultural data to be analyze covers wide time range, having various environmental conditions and from different farm locations [23]. Decision tree model might be very useful in this case allowing predictive models with high accuracy rates, ease of interpretation and stability which considered as discriminative model as compare with Naïve Bayes based on the Bayes Theorem as a generative model [24].

Based from the study of Adil et al., to acquire better yield and improved financial outcome, studying agricultural database that consists data about crop, rice field area, season, production rate and etc. is necessary. Analysis of large amount of agricultural data requires utilization of different data mining methods such as Decision tree, CART, Random Forest and etc. [25], compare and validate their result and select among them that provides high accuracy rating.

\section{METHODOLOGIES}

\subsection{Study Area}

The research study is conducted in the province of Quezon sprawled in an area of $8,707 \mathrm{~km}^{2}$. The province is divided in four (4) districts, consisting of two cities and 39 municipalities see Figure 1. Rice is the major food crop and staple food of the province aside from corn, vegetables and coconuts.

\subsection{Dataset Used}

The dataset used for the study were collected from different sources. Quezon Annual Harvesting Rice Data 2011-2018 recorded by the Quezon Provincial Agriculturist Office, Integrated Nutrient Management for Rice Crop data collected through Soil Laboratory and NPK data acquired from selected municipalities of Quezon using soil nutrient detector device. Dataset consist of nine attributes:

- Municipalities: includes data from all 41 municipalities of Quezon province

- Year: Annual rice harvest from 2011-2017 
- Season: Wet and Dry Season

- Area: Rice filed area cultivated measured in hectares

- Production rate: total rice yield per hectare from cultivated in tonne

- Ecosystem: Type of ecosystem of rice field, Irrigated; Rainfed Lowland; Rainfed Upland

- Seed type: type of rice variant being sown

- Soil pH: Level of acidity of soil sample tested from different rice fields

- NPK: level of soil nutrients tested using soil nutrient detector device

\begin{tabular}{|c|c|c|c|c|c|c|c|c|}
\hline \multirow[t]{2}{*}{ Municipality } & \multirow[t]{2}{*}{ Month } & \multirow[t]{2}{*}{ Year } & \multicolumn{2}{|c|}{ Season Avea Harvested } & \multirow{2}{*}{$\begin{array}{l}\text { Ave. Yield } \\
\text { (MT/Ha) }\end{array}$} & \multirow{2}{*}{$\begin{array}{l}\text { Production } \\
\text { MT }\end{array}$} & \multirow{2}{*}{ Ecosstem } & \multirow[t]{2}{*}{ Seed_tvpe } \\
\hline & & & & ( $\mathrm{Ha})$ & & & & \\
\hline 1 Burdeos & January & 2016 & Wet & 0.00 & 000 & 000 & Irrizated & Hybrid \\
\hline 2 General Nakar & January & 2016 & Wet & 0.00 & 000 & or & Irricated & Hybrid \\
\hline 3 Infanta & January & 2016 & Wet & 000 & 0.00 & 0.0 & Irricated & Hybrid \\
\hline 4 Jomalig & January & 2016 & Wet & 000 & 0.00 & 00 & Irrigated & Hybrid \\
\hline 5 lucban & lanuary & 2016 & Wet & 0.00 & 0.00 & oa & Irrigated & Hyorid \\
\hline 6 Mauban & January & 2016 & Wet & 000 & 000 & 00 & Irrigated & Hybrid \\
\hline 7 Pagbilas & January & 2016 & Wet & 000 & 0.00 & 00 & Irrigated & Hybrid \\
\hline 8 Panukulan & January & 2016 & Wet & 0.00 & 0.00 & 00 & Irrigated & Hybrid \\
\hline 9 Patnanunzan & January & 2016 & Wet & 0.00 & 0.00 & 00 & Irrigated & Hybrid \\
\hline 10 Polillo & January & 2016 & Wet & 000 & 0.00 & 00 & Irrigated & Hybrid \\
\hline 11 Real & January & 2016 & Wet & 0,00 & 0.00 & 00 & Irrizated & Hybrid \\
\hline 12 Sampalox & January & 2016 & Wet & 0,00 & 0.00 & 0.5 & Irrigated & Hybrid \\
\hline 13 Tapabas City & January & 2016 & Wet & 000 & 0,00 & 0,00 & Irrigated & Hybrid \\
\hline 14 Candelaria & January & 2016 & Wet & 45.00 & 4.16 & 187.40 & Irrigated & Hybrid \\
\hline 15 lucena City & January & 2016 & Wet & 114.00 & 4.40 & 501.80 & Irrigated & Hybrid \\
\hline $16 \operatorname{San}$ Antonio & January & 2016 & Wet & 000 & 0.00 & & Irrigated & Hybrid \\
\hline 17 Sariays & January & 2016 & Wet & 000 & 000 & 0,0 & Irrigated & Hybrid \\
\hline
\end{tabular}

Figure 3: Raw data of Annual Rice Harvest

\begin{tabular}{|c|c|c|c|c|c|c|c|c|c|c|c|}
\hline \multicolumn{12}{|c|}{ NTEGRATED NUTRIENT MANAGEMENT ACCOMIPLLSHIENT REPORT } \\
\hline Lin & Lab & Adtrow of $\mathrm{Famm}$ & Area & Crop/ / ge $_{0} /$ Varisty & Field Code & Lab & & & & & \\
\hline \multirow[t]{4}{*}{ No. } & No. & Musitipality City & (aas.) & & Remata & No. & pH & som. & $\mathrm{s}$ & P & $\mathrm{K}$ \\
\hline & & San Framaice & 1.0000 & Rise hybrid & & 7 & 7.14 & 3.5 & Medina & Medum & Hiph \\
\hline & 14 & Burdeos & 1.0000 & Risc inkred & & 14 & 6.02 & 0.5 & Low & Trase & Low \\
\hline & 16] & Tарақахуха & 20000 & Rise inked & Rice land & 16 & 5.11 & 1.8 & Low & Trase & Trase \\
\hline \multicolumn{12}{|c|}{ FEBRUARY } \\
\hline \multicolumn{12}{|c|}{ MARCH } \\
\hline & 99. & Paptlas & 0.5000 & Rise indred & thaba & 99 & 4.55 & 2.5 & Low & Trase & Low \\
\hline & 100 & Quezon & 0,5000 & Rise intred & & 100 & 6.00 & 2.5 & Medina & Low & Mediua \\
\hline & 101 & Gumasa & 1.0000 & Rise intred & & 101 & 5.86 & 3.0 & Medinas & High & $\mathrm{Hiqh}$ \\
\hline \multicolumn{12}{|c|}{\begin{tabular}{l|l} 
MAY & \\
\end{tabular}} \\
\hline & 132 & Burdeos & 2.5000 & Rise inbred & Sample A & 132 & 5.40 & 1.0 & Low & Trase & Low \\
\hline & 133 & Burdeon & 2.5000 & Rise inbred & Sample B & 133 & 5.89 & 1.0 & Low & Trase & Low \\
\hline \multicolumn{12}{|c|}{$\pi \mathrm{NE}$} \\
\hline & 180 & Candelaris & 1.0000 & Rise lybond & & 180 & 6.71 & 2.5 & Low & Low & Medium \\
\hline & 185 & Tryabas Cíty & 1.0000 & Rise lybrid & & 185 & 9.44 & 43 & Medina & Trase & Medinam \\
\hline & 193 & $S \approx n$ Andrea & 3.0000 & Rise hybrid & & 193 & 5.62 & 33 & Low & Trase & Low \\
\hline & & Catmauan & & & & & 8.00 & & Trace & High & Motina \\
\hline \multicolumn{12}{|c|}{ תiY } \\
\hline & 226 & Sen Narrato & 2.0000 & Rise intred & & 226 & 7.4 & 3.0 & Medrum & Medam & Modium \\
\hline & 227 & Pagstatuo & 1.5000 & Rise introd & Itans & 227 & 4.84 & 4.0 & Low & Low & Low \\
\hline & 232 & Sin Antceio & 5.0000 & Rise inked & & 232 & 6.79 & 4.3 & Mediuas | & Medux & Hiph \\
\hline
\end{tabular}

Figure 4: Raw data of Soils Lab results

The Figure 2 and 3 shown above are raw data obtained which contains unnecessary data and missing values needed to be cleaned. Dataset consists eight attributes; municipalities, month, year, season, area harvested(Ha), average yield(MT/Ha), production(MT), type of ecosystem and seed type. Other soil attributes were added such as ph, Nitrogen, Potassium and Phosphorus. During data cleaning and integration Talend software tool was used and file was saved with comma separated value (.csv) as file extension as shown in Figure 4.

\begin{tabular}{|c|c|c|c|c|c|c|c|c|c|}
\hline $\begin{aligned} & \text { No } \equiv \\
& \text { integer }\end{aligned}$ & $\begin{array}{r}\text { Municipality } \equiv \\
\text { city }\end{array}$ & $\begin{array}{r}\text { Month } 三 \\
\text { month }\end{array}$ & $\begin{array}{l}\text { Year } \equiv \\
\text { integer }\end{array}$ & $\begin{array}{l}\text { Season三 } \\
\text { compa... }\end{array}$ & $\begin{array}{r}\text { Area ha.... } \\
\text { decimal }\end{array}$ & $\begin{array}{r}\text { verage_... 三 } \\
\text { decimal }\end{array}$ & $\begin{array}{r}\text { Productio... } \\
\text { decimal }\end{array}$ & $\begin{array}{r}\text { Ecosystem } \\
\text { E } \\
\text { text }\end{array}$ & $\begin{array}{r}\text { Seed_Ty... } \\
\text { text }\end{array}$ \\
\hline & & & & & & & & & \\
\hline 222 & Calauag & July & 2016 & Dry & 2.75 & 2.91 & 8.00 & Irrigated & Hybrid \\
\hline 223 & Candelaria & July & 2016 & Dry & 51.97 & 4.03 & 209.34 & Irrigated & Inbred \\
\hline 224 & Lucena City & July & 2016 & Dry & 188.70 & 4.29 & 774.99 & Irrigated & Inbred \\
\hline 225 & Tiang & July & 2016 & Dry & 175.00 & 3.49 & 611.16 & Irrigated & Inbred \\
\hline 226 & Calauag & July & 2016 & Dry & 16.80 & 5.80 & 42.92 & Rainfed_Lowland & Hybrid \\
\hline 227 & Calauag & July & 2016 & Dry & 14.75 & 2.16 & 31.85 & Rainfed_Lowland & Inbred \\
\hline 228 & San Antonio & August & 2016 & Wet & 13.00 & 4.61 & 59.90 & Irrigated & Hybrid \\
\hline 229 & Calauag & August & 2016 & Wet & 1.00 & 2.80 & 2.80 & Irrigated & Hybrid \\
\hline 230 & Candelaria & August & 2016 & Wet & 123.05 & 3.90 & 480.29 & Irrigated & Inbred \\
\hline 231 & Lucena City & August & 2016 & Wet & 47.50 & 4.54 & 215.80 & Irrigated & Inbred \\
\hline
\end{tabular}

Figure 5: Data set after being cleansed and integrated

\subsection{Datasets Cleaning and Integration}

This phase involves testing and training of input data. The division of loaded data is divided into two sets with a ratio of 70 percent or 30 percent, such as 0.7 or 0.3 such as training data and test data. A classifier is used in a learning set to create the available input data. In this phase, construct the support data and preconceptions of the classifier to estimate and classify the function. Final data was formed through the use of machine learning module right after dataset preprocessing phase.

\subsection{Comparison of different algorithm}

Villanueva et al. defines accuracy refers to the degree of closeness of specific value being measured [26]. Precision is the measurement of exactness or quality, high precision rate means that the algorithm produces results substantially relevant than the irrelevant ones, while recall means that the algorithm produce most of the relevant outputs. Formulas in getting the Accuracy, Precision, Recall and F1 Score are shown in below:

\begin{tabular}{|c|c|}
\hline \multirow{2}{*}{\multicolumn{2}{|c|}{ Accuracy $=\frac{\mathrm{TP}+\mathrm{TN}}{\mathrm{TP}+\mathrm{TN}+\mathrm{FP}+\mathrm{FN}}$}} \\
\hline & \\
\hline \multicolumn{2}{|c|}{ Precision $=$ _... } \\
\hline prectsion & $\mathrm{Tp}+\mathrm{Fp}$ \\
\hline \multirow{2}{*}{ Recall $=$} & $\mathrm{Tp}$ \\
\hline & $\mathrm{Tp}+\mathrm{Fn}$ \\
\hline & $P \times R$ \\
\hline & $P+R$ \\
\hline
\end{tabular}




\section{RESULTS AND DISCUSSION}

The primary source of data particularly soil nutrient and annual rice harvest to be acquired from Soils Laboratory and Office of the Provincial Agriculturist of Quezon. Actual soil data and characteristics will be collected through soil testing procedure using Solar-powered Soil Nutrient Detector device [27] as shown in Figure 6. A portable rice field soil testing device used to determine the level of nutrient in the soil specifically Nitrogen, Phosphorus and Potassium. It could also collect other field data such as temperature, humidity, soil moisture and more.

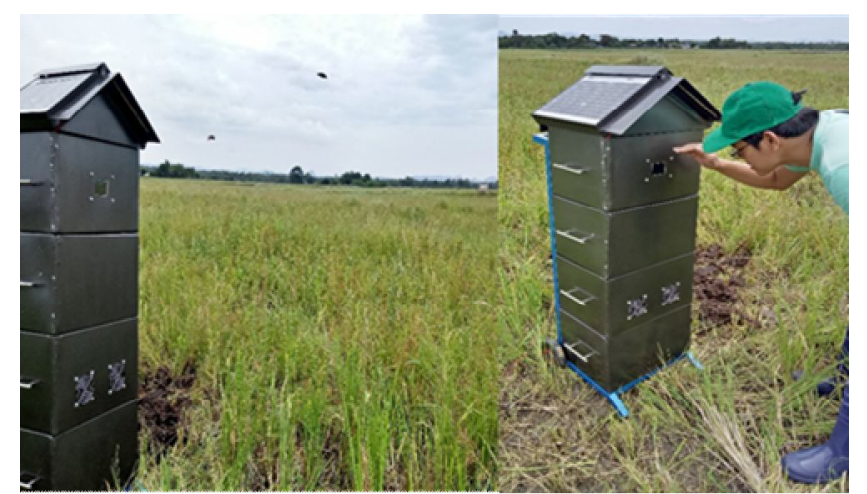

Figure 6: Actual rice field soil data collection using Solar-powered soil nutrient detector device

As shown in the Figure 7 is the overview of the methodology. Data collected from various sources was stored and integrated in a database to construct the required data sets. Through pre-processing phase, removal of irregular and unwanted data will be done. For data cleaning and integration, Talend an ETL tool is used.

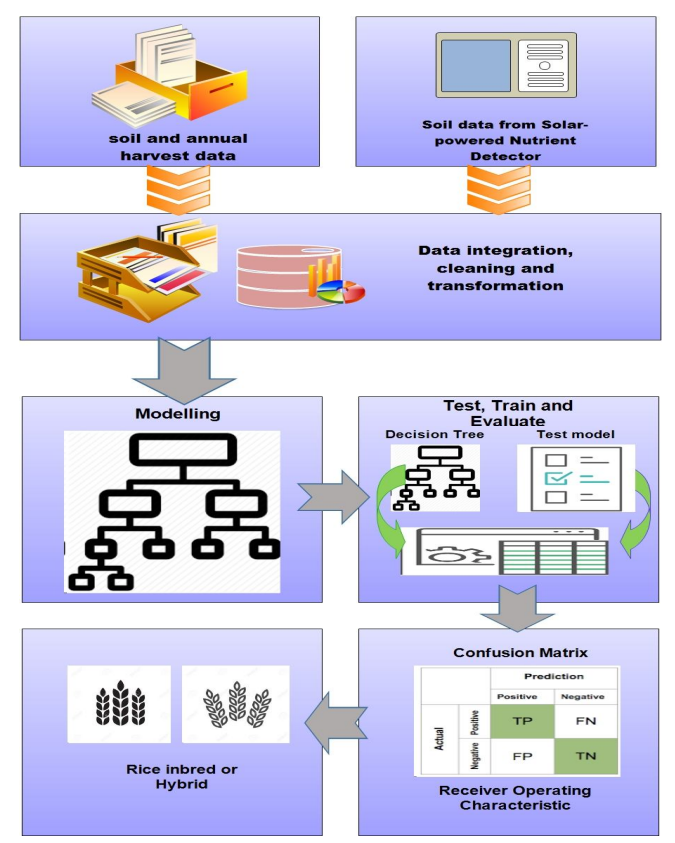

Figure 7: The overview of the methodology used
Attribute values was extracted from datasets such as municipality, month of soil testing, season, area, yield, type of ecosystem, soil nutrient, rice crop variant, etc. Extracting features and useful information coming from existing data is the most important phase. Application and testing of various classification algorithm methodology was done to find the most accurate model for developing a rice crop classification and predictive model. To uncover the accurate classification model through data analysis, WEKA and Python an open source data mining software package and was used. The next step is to create the confusion matrix to examine and determine how well the classifier will recognize if two classes are confused by the model. It will show a tabular display for assessing the predictive accuracy of a predictive model resulting in rice crop variety identification.

\section{CONCLUSION}

Data from different sources were integrated, stored and pre-processed. Various classification algorithms of data mining were tested and applied on the rice harvest and rice field soil data. The algorithms ID3, C4.5, Naive Bayes and Classification and Regression Tree are applied on annual rice field data set and soil dataset.

In this study, Jupyter Notebook an open-source web-based application was used allows to create documents containing live codes, equations, visualization and text. Used for data cleaning, transformation, simulation, data visualization, statistical modelling, machine learning and more.

Table 1: Comparison Table of Different Algorithm

\begin{tabular}{|l|r|r|r|r|}
\hline & Accuracy & Precision & \multicolumn{1}{|c|}{ Recali } & F1 Scora \\
\hline Improve-CART & $95.22 \%$ & 0.99 & 0.93 & 0.96 \\
\hline C4.5 & $40.57 \%$ & 0.50 & 0.03 & 0.06 \\
\hline 103 & $70.75 \%$ & 0.72 & 0.83 & 0.77 \\
\hline Nañe Baves & $62.26 \%$ & 0.85 & 0.44 & 0.58 \\
\hline
\end{tabular}

The performance and accuracy of various algorithm were validated and found out that Classification and Regression Tree was quite a lot better among other algorithms. CART received the highest accuracy rate of $(95.22 \%)$ as compared with Naïve Bayes rating of $(62.26 \%)$, ID3 with $(70.75 \%)$ and $\mathrm{C} 4.5$ having the lowest rating of $(40.57 \%)$. However, better results can be achieved by updating the training data and validation year. For further research, the development of web-based application utilizing the suitable algorithm from this study will be very useful in the agricultural field most specifically in rice crop production and could provide useful information to help farmers in choosing the right rice crop variant having the bigger productivity rate before planting. 


\section{ACKNOWLEDGEMENT}

The author acknowledges the support and effort of Provincial Agriculturist Office of Quezon, Department of Science and Technology 4A, Center for Hazard and Environmental Resource Mapping (CHERM), Southern Luzon State University by providing the necessary information and Commission on Higher Education for financial support for the realization of the study.

\section{REFERENCES}

1. T. Lafarge and C. S. Bueno, "Field Crops Research Higher crop performance of rice hybrids than of elite inbreds in the tropics: 2 . Does sink regulation, rather than sink size , play a major role ?," vol. 114, pp. 434-440, 2009.

https://doi.org/10.1016/j.fcr.2009.08.011

2. A. N. M. R. K. Bhuiyan, Sadiqul I., Increasing Rice Production in Bangladesh. 1271 Makati City, Philippines: International Rice Research Institute.

3. "A Review of the Agriculture Sector in CALABARZON,"

https://psa.gov.ph/content/review-agriculture-sector -calabarzon. .

4. Https://www.pna.gov.ph/articles/1035786, "Bigger PH palay harvest seen in first half of 2018." .

5. R. Romanillos, "Rice-Based Agroforestry Technology: A Strategy in Optimizing Agricultural Productivity and Income in Marginalized Inland Valleys in Quezon Province," no. February, 2016.

6. Https://business.inquirer.net/209793/quezon -farms -get-boost-new-irrigation-facility, "Quezon farms get boost from new irrigation facility." .

7. E. Communications and K. R. S. Preethaa, "Predictive Analysis in Agriculture to Improve the Crop Productivity using ZeroR algorithm," vol. 2, no. 2, pp. 1397-1401, 2016.

8. H. R. Lucero and L. Lacatan, "Utilizing Smart Space Technology for Precision Agriculture," no. 5640, pp. 5640-5648, 2020.

9. P. Fernando and L. Lacatan, "Microcontroller-Based Soil Nutrients Analyzer for Plant Applicability using Adaptive Neuro-Fuzzy Inference System,” no. 5576, pp. 5576-5581, 2020.

10. V. M. Reddy and I. A. Babu, "Advanced Trends in Computer Science and," vol. 8, no. 1, pp. 42-44, 2019.

https://doi.org/10.1111/oet.9_12596

11. M. June and R. E. Talingting, "International Journal of Advanced Trends in Computer Science and Engineering A Data Mining-driven Model for Job Satisfaction Prediction of School Administrators in DepEd Surigao del Norte Division," vol. 8, no. 3, 2019.

12. S. H. Ganesh, B. D. P. Cindrella, C. A. J. Christy, M.
Scholar, and R. Scholar, "International Journal of Computer Science and Mobile Computing A REVIEW ON CLASSIFICATION TECHNIQUES OVER AGRICULTURAL DATA A," Int. J. Comput. Sci. Mob. Comput., vol. 4, no. 5, pp. 491-495, 2015.

13. M. Yousaf et al., "Effects of fertilization on crop production and nutrient-supplying capacity under rice-oilseed rape rotation system," Sci. Rep., no. September 2016, pp. 1-9, 2017.

https://doi.org/10.1038/s41598-017-01412-0

14. Z. Qi-chun and W. Guang-huo, "Studies on nutrient uptake of rice and characteristics of soil microorganisms in a long-term fertilization experiments for irrigated rice *," no. 2, pp. 147-154, 2005.

https://doi.org/10.1631/jzus.2005.B0147

15. S. K. Gosal, G. K. Gill, S. Sharma, and S. S. Walia, "Soil Nutrient Status and Yield of Rice as affected by long term integrated use of organic and inorganic fertilizers," vol. 4167, no. November, 2017. https://doi.org/10.1080/01904167.2017.1392570

16. A. R. Varieties, A. R. Breeding, T. Force, A. R. Breeding, T. Force, and B. Faso, "19 Intellectual assets generated by AfricaRice under TAAT 1.," pp. $1-41,2016$.

17. S. K. Dubey, "Farmers' preference to rice varieties Farmers ' preferences to varietal attributes as an indicator for acceptance and adoption of aromatic rice ( Oryza sativa ) varieties," no. January, 2017.

18. M. Amin, B. Mohd, and E. Jahanshiri, "GIS based System for Paddy Precision Farming," no. Aug 2008.

19. E. Kannan, A. Paliwal, and A. Sparks, Spatial and Temporal Patterns of Rice Production and Productivity. Elsevier Inc., 2017.

20. G. T. Ayehu and S. A. Besufekad, "Land Suitability Analysis for Rice Production: A GIS Based Multi-Criteria Decision Approach," no. January, 2015.

21. R. Poonia and S. Bhargava, "Prediction of Crops Methodology using Data," pp. 19832-19838, 2017.

22. Raorane A.A and Kulkarni R.V, "Data Mining: An effective tool for yield estimation in the agricultural sector," Int. J. Emerg. Trends Technol. Comput. Sci., vol. 1, no. 2, 2012.

23. M. Iwańska, A. Oleksy, M. Dacko, B. Skowera, and T. Oleksiak, "Use of classification and regression trees ( CART ) for analyzing determinants of winter wheat yield variation among fields in Poland," vol. 55, no. 2, pp. 197-214, 2018.

https://doi.org/10.2478/bile-2018-0013

24. K. Andana, E. K. Andana, M. Othman, and R. Ibrahim, "of Advanced Trends Computer Engineering Comparative Analysis of Text Classification Using Naive Bayes and Support Vector Machine in Detecting Negative Content in Indonesian Twitter," vol. 8, no. 1, 2019.

https://doi.org/10.30534/ijatcse/2019/6481.32019 
25. N. Adil, S. Dewangan, and K. Sharma, "Efficient Classification And Regression Techniques To Predict Crop Yield," vol. 8, no. 11, 2019.

26. J. A. Villanueva, "Malware Predictor using Machine Learning Techniques," no. 5665, pp. 5665-5674, 2020.

27. A. N. Natividad and L. L. Lacatan, "Solar-Powered Soil Nutrient Detector for Rice Field," no. 4267, pp. 4267-4276, 2020. 